\title{
Craniofacial Surgery for Esthesioneuroblastoma: Report of an International Collaborative Study
}

Snehal G. Patel, M.D. ${ }^{1}$ Bhuvanesh Singh, M.D. ${ }^{1}$ Hilda E. Stambuk, M.D. ${ }^{2}$ Diane Carlson, M.D. ${ }^{3}$ Patrick G. Bridger, M.D. ${ }^{4}$ Giulio Cantu, M.D. ${ }^{5}$ Anthony D. Cheesman, F.R.C.S. ${ }^{6}$ Paul Donald, M.D. ${ }^{7}$ Dan Fliss, M.D. ${ }^{8}$ Patrick Gullane, M.D. ${ }^{9}$ Shin-etsu Kamata, M.D. ${ }^{10}$ Ivo Janecka, M.D. ${ }^{11}$ Luiz P. Kowalski, M.D. ${ }^{12}$ Dennis H. Kraus, M.D. ${ }^{1}$ Paul A. Levine, M.D. ${ }^{13}$ Luiz R. Medina, M.D. ${ }^{14}$ Sultan Pradhan, M.D. ${ }^{15}$ Victor Schramm, M.D. ${ }^{16}$ Carl Snyderman, M.D. ${ }^{17}$ William I. Wei, M.D., M.S., F.R.C.S., F.R.C.S.Ed. ${ }^{18}$ Jatin P. Shah, M.D. ${ }^{1}$

${ }^{1}$ Department of Surgery, Memorial Sloan Kettering Cancer Center,

Address for correspondence and reprint requests Jatin P. Shah, M.D., New York

2 Department of Radiology, Memorial Sloan Kettering Cancer, New York F.A.C.S., Chief, Head and Neck Service, Memorial Sloan-Kettering Cancer Center, 1275 York Avenue, New York, NY 10021

${ }^{3}$ Laboratory Medicine/Pathology, Cleveland Clinic, Weston, Florida (e-mail: shahj@mskcc.org).

${ }^{4}$ Prince of Wales Hospital, Sydney, New South Wales, Australia

${ }^{5}$ Instituto Nazionale, Milan, Italy

${ }^{6}$ The Royal National Throat, Nose, and Ear Hospital, London,

United Kingdom

${ }^{7}$ UC Davis, Davis, California

${ }^{8}$ Department of Otolaryngology, Tel Aviv Sourasky Medical Center, Tel Aviv, Israel

${ }^{9}$ Department of Otolaryngology-Head and Neck Surgery, University of Toronto, Toronto, Canada

${ }^{10}$ Cancer Institute Hospital, Tokyo, Japan

11 Massachusetts Eye and Ear Hospital, Boston, Massachusetts

12 Hospital do Cancer AC Camargo, Sao Paulo, Brazil

13 University of Virginia Health System, Charlottesville, Virginia

${ }^{14}$ Hospital das Clinicas, Sao Paulo, Brazil

${ }^{15}$ Tata Memorial Hospital, Mumbai, India

${ }^{16}$ Center for Head and Neck Surgery, Denver, Colorado

17 University of Pittsburgh, Pittsburgh, Pennsylvania

${ }^{18}$ University of Hong Kong, Hong Kong

J Neurol Surg B 2012;73:208-220.
Abstract
Keywords
- nose neoplasms/ mortality/pathology/ surgery/*therapy
- esthesioneuro- blastoma
- olfactory/*therapy
- combined modality therapy
- radiotherapy
- adjuvant
- survival analysis

Introduction Impact of treatment and prognostic indicators of outcome are relatively ill-defined in esthesioneuroblastomas (ENB) because of the rarity of these tumors. This study was undertaken to assess the impact of craniofacial resection (CFR) on outcome of ENB.

Patients and Methods Data on 151 patients who underwent CFR for ENB were collected from 17 institutions that participated in an international collaborative study. Patient, tumor, treatment, and outcome data were collected by questionnaires and variables were analyzed for prognostic impact on overall, disease-specific and recurrence-free survival. The majority of tumors were staged Kadish stage C (116 or 77\%). Overall, 90 patients (60\%) had received treatment before CFR, radiation therapy in 51 (34\%), and chemotherapy in 23 (15\%). The margins of surgical resection were reported positive in $23(15 \%)$ patients. Adjuvant postoperative radiation therapy was used in 51 (34\%) and chemotherapy in 9 (6\%) patients. received

June 28, 2011

accepted

July 12, 2011

published online

May 7, 2012
Copyright $\odot 2012$ by Thieme Medical Publishers, Inc., 333 Seventh Avenue, New York, NY 10001, USA. Tel: +1(212) 584-4662.
DOI http://dx.doi.org/ 10.1055/s-0032-1311754. ISSN 2193-6331. 
Results Treatment-related complications were reported in 49 (32\%) patients. With a median follow-up of 56 months, the 5-year overall, disease-specific, and recurrence-free survival rates were 78,83 , and $64 \%$, respectively. Intracranial extension of the disease and positive surgical margins were independent predictors of worse overall, diseasespecific, and recurrence-free survival on multivariate analysis.

Conclusion This collaborative study of patients treated at various institutions across the world demonstrates the efficacy of CFR for ENB. Intracranial extension of disease and complete surgical excision were independent prognostic predictors of outcome.

Although esthesioneuroblastoma (ENB) is a relatively uncommon neoplasm of the nasal vault, this tumor has generated considerable interest in recent medical literature due to several controversies related to the cell of origin, histologic diagnosis, clinical behavior and staging, treatment, and outcomes. ${ }^{1,2}$ Central to these controversies is the fact that ENB belong to a spectrum of malignant tumors with neuroendocrine differentiation which has resulted in diversity in reporting clinical behavior. ${ }^{3,4}$ The advent of immunohistochemical staining (IHC) and electron microscopy (EM) have improved classification of this group of tumors, and a recent report has in fact documented the high rate of reclassification of "ENB" when examined by an experienced pathologist using IHC and EM. ${ }^{5,6}$ This observation is of particular significance in evaluating the clinical behavior and results of treatment reported in the literature.

In spite of the controversies surrounding management of ENB, there is a little doubt that combined modality treatment using surgical resection and radiation therapy provides the best results in terms of control of disease and survival. Until craniofacial resection (CFR) became available as surgical treatment for $\mathrm{ENB}^{7}{ }^{7}$ extracranial transfacial approaches have been standard for surgical resection. The use of CFR in management of ENB has been documented to improve outcomes not only as evidenced by the comparison of recent reports with historical reports, but also at the same institution over time. ${ }^{8}$ Most reports in the literature however, are based on a small number of patients treated over a long period of time with varying treatment regimens. Identification of independent prognostic predictors using multivariate analysis has therefore not been possible. The purpose of this study was to evaluate the efficacy of CFR in a multi-institutional international cohort of a large number of patients with ENB. We were also able to analyze this cohort in multivariate analysis to identify independent predictors of outcome after CFR.

\section{Patients and Methods}

A multi-item questionnaire was sent out to 17 participating investigators from various parts of the world to obtain information on patient, tumor, treatment variables, and outcomes of treatment. Completed data sheets on patients treated between October 1956 and January 2000 were submitted by each investigator to the central analyzing office for data entry, compilation, and statistical analysis.

\section{Data Entry, Patient Exclusions, and Statistical Methods}

Data were entered into a commercially available spreadsheet (Microsoft Excel 2000, Microsoft Corporation) and statistical analysis was performed using a computerized software package (JMP version 4.0, SAS Institute Inc., Cary, NC). The total number of patients collected from all contributors was 1541 . Of these, 114 had to be excluded either because of no information on pathology $(n=26)$ or lack of follow-up data $(n=88)$. After these exclusions, a total of 1427 patients were eligible for analysis. Of the 1427 analyzable patients, 120 had benign tumors and have been excluded in this analysis. We have previously reported the results of CFR in the 1307 patients with malignant tumors of the skull base $\mathrm{e}^{9}$ and this report focuses on the 151 patients from this group who had the histological diagnosis of ENB.

The follow-up interval was calculated in months from the date of CFR to the date of last follow-up or death and recurrence-free interval was calculated from the date of CFR to that of first recurrence. For disease-specific survival, patients who reportedly died of non-cancer-related causes (7/151 or $4.6 \%$ ) and those who were alive with disease at last follow-up (16/ 151 or $10.6 \%$ ) were censored. Recurrence-free (RFS), overall (OS), and disease-specific (DSS) survival rates were calculated using the Kaplan-Meier method and univariate comparisons between groups were performed using the log-rank test. A $p$ value of 0.05 or less was considered significant and significant factors were entered into multivariate analysis using the Cox proportional hazards model. Nonparametric qualitative and quantitative comparisons were performed using the Fisher exact test and Mann-Whitney U test, respectively.

\section{Patient Demographics}

Patients ranged in age from 12 to 82 years with a median of 49.5 years. - Table 1 presents the demographic data on these patients.

\section{Primary Tumor}

The anatomic extent of the primary tumor is listed in -Table 2. The Kadish stage was directly reported by the 
Table 1 Patient Demographics

\begin{tabular}{|l|l|l|l|}
\hline & & No. of Patients & Percent \\
\hline Age & Range: 12-82 yr (Median = 49.5 yr) & & \\
\hline Age groups & $<20 \mathrm{yr}$ & 10 & $6.6 \%$ \\
& $21-40 \mathrm{yr}$ & 41 & $27.1 \%$ \\
& $41-70 \mathrm{yr}$ & 88 & $58.3 \%$ \\
& $>70 \mathrm{yr}$ & 3 & $6.0 \%$ \\
& Missing information & 88 & $2.0 \%$ \\
\hline Gender & Male & 58 & $58.3 \%$ \\
& Female & 5 & $38.4 \%$ \\
& Missing information & 142 & $3.3 \%$ \\
\hline Medical comorbidity & None & 8 & $94.0 \%$ \\
& Present & 1 & $5.3 \%$ \\
& Missing information & $0.7 \%$ \\
\hline
\end{tabular}

Table 2 Location and Extent of the Primary Tumor

\begin{tabular}{|l|l|l|l|}
\hline & & No. of Patients & Percent \\
\hline Orbital involvement & None & 81 & $53.6 \%$ \\
& Bone & 43 & $28.5 \%$ \\
& Periosteum & 15 & $9.9 \%$ \\
& Intraorbital contents & $6.6 \%$ \\
& Missing information & 2 & $1.4 \%$ \\
\hline Intracranial extension & None & 93 & $61.6 \%$ \\
& Present & 56 & $37 \%$ \\
& Missing information & 2 & $1.4 \%$ \\
\hline Cranial Nerve Deficits & None & 135 & $89.4 \%$ \\
& Present & 14 & $9.2 \%$ \\
\hline Kadish Stage & Missing information & 2 & $1.4 \%$ \\
$(n=151)$ & Stage A/B & 33 & $21.9 \%$ \\
& Stage C & 2 & $76.7 \%$ \\
\hline
\end{tabular}

contributors in only 36 of the 151 patients (23.8\%). A total of 133 patients $(74.8 \%$ ) could be retrospectively staged based on available information on orbital and intracranial extent while 2 (1.3\%) lacked sufficient information for staging. No orbital or intracranial involvement was reported in 33 patients, but details on anatomic extent of tumor were not precise enough to stratify them into Kadish stage A and B. This group was therefore analyzed as Kadish stage A/B.

\section{Treatment}

Most patients had undergone some form of treatment before CFR (-Table 3). The details of prior radiation therapy were

Table 3 Previous Treatment

\begin{tabular}{|c|c|c|c|}
\hline & & No. of Patients & Percent \\
\hline Prior treatment & $\begin{array}{l}\text { None } \\
\text { Yes }\end{array}$ & $\begin{array}{l}61 \\
90\end{array}$ & $\begin{array}{l}40.4 \% \\
59.6 \%\end{array}$ \\
\hline Previous surgery & $\begin{array}{l}\text { None } \\
\text { Yes }\end{array}$ & $\begin{array}{l}101 \\
50\end{array}$ & $\begin{array}{l}66.9 \% \\
33.1 \%\end{array}$ \\
\hline Previous radiation therapy & $\begin{array}{l}\text { None } \\
\text { Yes }\end{array}$ & $\begin{array}{l}100 \\
51\end{array}$ & $\begin{array}{l}66.2 \% \\
33.8 \%\end{array}$ \\
\hline Previous chemotherapy & $\begin{array}{l}\text { None } \\
\text { Yes } \\
\text { Missing information }\end{array}$ & $\begin{array}{l}127 \\
23 \\
1\end{array}$ & $\begin{array}{l}84.1 \% \\
15.2 \% \\
0.7 \%\end{array}$ \\
\hline
\end{tabular}


Table 4 Adjuvant Treatment

\begin{tabular}{|l|l|l|l|}
\hline & & No. of Patients & Percent \\
\hline Adjuvant radiation therapy & No & 79 & $52.3 \%$ \\
& Yes & 71 & $47.0 \%$ \\
& Missing information & 1 & $0.7 \%$ \\
\hline Adjuvant chemotherapy & No & 140 & $92.7 \%$ \\
& Yes & 9 & $6.0 \%$ \\
& Missing information & 2 & $1.3 \%$ \\
\hline
\end{tabular}

Table 5 Details of Surgical Treatment

\begin{tabular}{|l|l|l|l|}
\hline & & No. of Patients & Percent \\
\hline Margins of surgical resection & Negative & 102 & $67.6 \%$ \\
& Close & 20 & $13.2 \%$ \\
& Positive & 23 & $15.2 \%$ \\
& Missing information & 6 & $4.0 \%$ \\
\hline Reconstruction & No & 19 & $12.6 \%$ \\
& Yes & 6 & $83.4 \%$ \\
& Missing information & 39 & $4.0 \%$ \\
\hline Type of reconstruction & Autologous nonvascularized tissue & 23 & $31.0 \%$ \\
(in 126 patients) & Free flaps & 62 & $18.2 \%$ \\
& Locoregional flaps & 2 & $49.2 \%$ \\
& Nonvascularized bone & $1.6 \%$ \\
\hline
\end{tabular}

available in 49 patients (96\%), and the dose ranged from 1800 to $9000 \mathrm{cGy}$ with a median of $5000 \mathrm{cGy}$.

Adjuvant postoperative radiotherapy was used in 71 patients (47\%); a median dose of $5870 \mathrm{cGy}$ was administered (range: 2800 to $6200 \mathrm{cGy}$ ). Adjuvant chemotherapy was used in nine patients (5.9\%) (-Table 4 ).

\section{Follow-Up}

The follow-up interval ranged from 1 to 323 months with a median of 56 months. The period of follow-up was less than 5 years in 92 patients (61\%) while 59 patients (39\%) were followed up for longer than 5 years. Of the 117 patients who were alive, 52 (44.4\%) had a longer than 5-year follow-up.

\section{Results}

- Table 5 lists the details of surgical excision, reconstruction, and margin status. Overall, $32.5 \%$ of patients were recorded to have developed a postoperative complication (-Table 6 ). The commonest complications were related to the central nervous system or local wound while the postoperative mortality rate was $1.3 \%$.

Table 6 Postoperative Complications Following Craniofacial Resection

\begin{tabular}{|c|c|c|c|}
\hline & & No. of Patients & Percent \\
\hline Complication & $\begin{array}{l}\text { No } \\
\text { Yes } \\
\text { Missing information }\end{array}$ & $\begin{array}{l}101 \\
49 \\
1\end{array}$ & $\begin{array}{l}66.8 \% \\
32.5 \% \\
0.7 \%\end{array}$ \\
\hline Wound complications & $\begin{array}{l}\text { No } \\
\text { Yes }\end{array}$ & $\begin{array}{l}128 \\
22\end{array}$ & $\begin{array}{l}84.7 \% \\
14.6 \%\end{array}$ \\
\hline Central nervous system complications & $\begin{array}{l}\text { No } \\
\text { Yes }\end{array}$ & $\begin{array}{l}121 \\
29\end{array}$ & $\begin{array}{l}80.1 \% \\
19.2 \%\end{array}$ \\
\hline Systemic complications & $\begin{array}{l}\text { No } \\
\text { Yes }\end{array}$ & $\begin{array}{l}146 \\
4\end{array}$ & $\begin{array}{l}96.7 \% \\
2.6 \%\end{array}$ \\
\hline Orbital complications & $\begin{array}{l}\text { No } \\
\text { Yes }\end{array}$ & $\begin{array}{l}148 \\
2\end{array}$ & $\begin{array}{l}98.0 \% \\
1.3 \%\end{array}$ \\
\hline Postoperative mortality & $\begin{array}{l}\text { No } \\
\text { Yes }\end{array}$ & $\begin{array}{l}149 \\
2\end{array}$ & $\begin{array}{l}98.7 \% \\
1.3 \%\end{array}$ \\
\hline
\end{tabular}


With a median follow-up of 56 months (range: 1 to 323 months), the 5-year OS and DSS rates calculated using the Kaplan-Meier method were 77.7 and $82.6 \%$, respectively (-Fig. 1). The median time to recurrence after CFR was 16 months (1 to 140 months) and the 5-year RFS was $64.2 \%$. The majority of the 106 patients $(84 / 106$ or $79.2 \%)$ who were recurrence-free had been followed up for an interval (median 46 months) longer than the median time to recurrence.

On multivariate analysis, intracranial extension of the disease, and close or positive margins of surgical excision were the only independent predictors of worse DSS (-Table 7) and OSS (-Table 8). Intraorbital extension of tumor was an additional independent predictor of RFS (-Table 9). Kadish stage was analyzed in a multivariate model that did not include intraorbital and intracranial extension, and was not an independent predictor of any of the three outcomes.

\section{Discussion}

Existing reports on ENB from individual institutions are based on small numbers of patients since the tumor is uncommon. As with other uncommon tumors, reporting outcomes becomes difficult and patients treated over long periods of time have to be studied to accumulate reasonable numbers. This introduces heterogeneity in the study population because diagnostic and therapeutic modalities evolve with time. Additionally, for a tumor such as ENB, there has been a major evolution in histological diagnosis with the realization that ENB belongs to a spectrum of neuroendocrine tumors that have varying clinical behavior. If all of these issues are taken into account, it is not surprising that there is considerable difficulty in comparing reported series which adds to the confusion regarding the clinical behavior, treatment, and outcomes in ENB.

Histologic features of ENB have been used for prognostic prediction in Hyam's classification. ${ }^{10-13}$ Low-grade tumors grow in discrete lobules and nests of uniform small round blue cells, without significant nuclear pleomorphism or

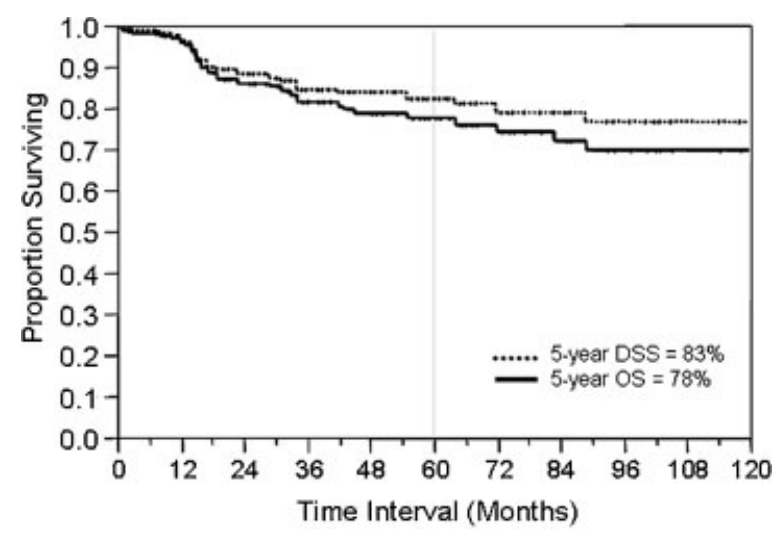

Figure 1 With a median follow-up of 56 months, the 5-year overall and disease-specific survival rates calculated by the Kaplan-Meier method were $78 \%$ and $83 \%$ respectively. necrosis, with only rare mitoses and with a fibrillary background. The eosinophilic, delicate neurofibrillary stroma may be concentrically surrounded by the small blue cells, forming Homer Wright rosettes or even Flexner rosettes (those without central lumen versus those with central lumen). These tumors are readily identifiable under the light microscope and were traditionally assigned lower grades on Hyam's classification. As these tumors become higher grade as indicated by marked necrosis, loss of the neurofibrillary matrix and abundant mitoses, accurate distinction from other malignant neoplasms becomes increasingly difficult, especially on light microscopy. The differential diagnosis then expands to include sinonasal undifferentiated carcinoma (SNUC), sinonasal undifferentiated neuroendocrine carcinoma (SNEC), lymphoma, rhabdomyosarcoma, desmoplastic small round cell tumor, as well as melanoma. These tumors have a considerably more aggressive clinical course compared with ENB and it is possible that some patients with one of these tumors may have been classified as Hyam's grade III or IV ENB in the past. This may account for the variable behavior and poor outcome reported for ENB in some older series.

Although the differential diagnosis has been facilitated by modern technology, it is important to remember that ENB does not have a unique, pathognomonic immunophenotype; rather one must, in conjunction with the morphological appearance, interpret a panel of antibody reactivity, which can be variable. For instance, epithelial membrane antigen (EMA) is generally negative in ENB, whereas up to $65 \%$ of SNUC will stain positively. ${ }^{14} \mathrm{~S}-100$ protein should only stain in a sustentacular-type pattern in ENB; not staining the majority of tumor cells, as one would expect in a melanoma, for instance. Neuron-specific enolase is almost always positive, however, variable reactivity may be seen with chromogranin and synaptophysin. The majority of cases would however be expected to be at least synaptophysin positive. It is now known that ENB is distinct from the Ewing sarcoma family of tumors. ${ }^{15}$ ENB should therefore be negative for the antibody 013 (CD99), which is directed against the Ewing sarcoma-associated MIC2 antigen.

Basal cells in the olfactory epithelium have been identified to express neural cell adhesion molecule (NCAM), and the human homologue of the Drosophila achaete-scute (MASH) gene complex. ${ }^{2}$ Carney et al $^{16}$ identified expression of the human achaete-scute 1 (hASH) gene in ENB, which is the human homologue of MASH. Human achaete-scute homologue gene 1 has been shown to play a crucial role in endocrine/neuroendocrine determination and differentiation in normal development of the nervous system, as well as malignancies including small cell carcinoma of the lung and prostate, neuroblastoma, and medullary carcinoma of the thyroid. ${ }^{17}$ Mhawech et al $^{18}$ were able to identify hASH1 mRNA using RT-PCR, in ENB, paving the way for future molecular diagnostic developments in the identification and diagnosis of ENB.

A better understanding of the genetic and molecular mechanisms underlying the development of ENB will undoubtedly improve our ability to predict prognosis. In current clinical practice, however, staging and predicting outcomes 
Table 7 Prognostic Factors for Disease-Specific Survival

\begin{tabular}{|c|c|c|c|c|}
\hline Variable & $\begin{array}{l}\text { No. of } \\
\text { Patients }\end{array}$ & $\begin{array}{l}\text { 5-Year Disease } \\
\text { Specific Survival }\end{array}$ & $\begin{array}{l}\text { Univariate Analysis } \\
\text { (Log-Rank Test) }\end{array}$ & $\begin{array}{l}\text { Multivariate Analysis* } \\
\text { Relative Risk ( } 95 \% \text { Confidence } \\
\text { Intervals) }\end{array}$ \\
\hline Age & & & & - \\
\hline$<50 \mathrm{yr}$ & 77 & $82.6 \%$ & 0.7 & \\
\hline$>50 \mathrm{yr}$ & 71 & $82.2 \%$ & & \\
\hline Gender & & & & - \\
\hline Female & 58 & $81.6 \%$ & 0.5 & \\
\hline Male & 88 & $83.6 \%$ & & \\
\hline Medical problems & & & & - \\
\hline None & 142 & $81.4 \%$ & 0.2 & \\
\hline Yes & 8 & $100 \%$ & & \\
\hline Intraorbital extension & & & & - \\
\hline None & 139 & $83.9 \%$ & 0.04 & \\
\hline Present & 10 & $56.2 \%$ & & \\
\hline Intracranial extension & & & & 1 \\
\hline None & 93 & $89.0 \%$ & 0.001 & $3.3(1.4-7.7)$ \\
\hline Present & 56 & $69.8 \%$ & & $p=0.007$ \\
\hline Kadish stage & & & & - \\
\hline Stage A/B & 33 & $96.5 \%$ & 0.04 & \\
\hline Stage C & 116 & $78.7 \%$ & & \\
\hline Previous surgical manipulation & & & & - \\
\hline No & 101 & $77.6 \%$ & 0.02 & \\
\hline Yes & 50 & $92.7 \%$ & & \\
\hline Previous radiation therapy & & & & - \\
\hline \multicolumn{5}{|l|}{ No } \\
\hline \multirow[t]{2}{*}{ Yes } & 100 & $81.3 \%$ & 0.2 & \\
\hline & 51 & $85.3 \%$ & & \\
\hline Previous chemotherapy & & & & - \\
\hline No & 1 & & & \\
\hline Yes & 27 & $83.5 \%$ & 0.5 & \\
\hline NoNYes & 23 & $78.9 \%$ & & \\
\hline \multicolumn{5}{|l|}{ Surgical margins } \\
\hline Negative & 102 & $88.8 \%$ & 0.009 & 1 \\
\hline \multirow[t]{2}{*}{ Positive (including close) } & 43 & $69.9 \%$ & & $2.4(1.1-5.3)$ \\
\hline & & & & $p=0.04$ \\
\hline
\end{tabular}

"Kadish Stage and intraorbital and intracranial extension were analyzed in two mutually exclusive models.

for ENB is based on assessment of the anatomic extent of the tumor. The Kadish system ${ }^{19}$ is one such staging paradigm that was proposed based on observations in a very small number of patients. The categorization into three stages had to be crude because cross-sectional anatomic imaging was not available at the time. Modern day imaging techniques including computed tomography (CT) and magnetic resonance imaging (MRI) allow very precise delineation of anatomy and mapping of tumor extent, and as a result several other staging systems have been proposed..$^{20-23}$
Radiologic imaging is crucial in not only estimating the extent of disease, but also in planning treatment. CT and MRI generally complement each other, and should be used to examine specific issues such as bone involvement, inflammatory disease versus tumor, intraorbital or intracranial extension. Thin-section contrast-enhanced axial and coronal CT scan is generally the initial imaging modality since it is a quick examination that allows for the most accurate assessment of the bony structures of the paranasal sinuses and skull base (-Fig. 2A). Staging of the tumor can be accomplished 
Table 8 Prognostic Factors for Overall Survival

\begin{tabular}{|c|c|c|c|c|}
\hline Variable & $\begin{array}{l}\text { No. of } \\
\text { Patients }\end{array}$ & $\begin{array}{l}\text { 5-Year Overall } \\
\text { Survival }\end{array}$ & $\begin{array}{l}\text { Univariate Analysis } \\
\text { (Log-Rank Test) }\end{array}$ & $\begin{array}{l}\text { Multivariate Analysis* } \\
\text { Relative Risk ( } 95 \% \text { Confidence } \\
\text { Intervals) }\end{array}$ \\
\hline Age & & & & - \\
\hline$<50 \mathrm{yr}$ & 77 & $77.7 \%$ & 0.9 & \\
\hline$>50 \mathrm{yr}$ & 71 & $77.2 \%$ & & \\
\hline Gender & & & & - \\
\hline Female & 58 & $71.1 \%$ & 0.5 & \\
\hline Male & 88 & $82.2 \%$ & & \\
\hline Medical problems & & & & - \\
\hline None & 142 & $78.8 \%$ & 0.09 & \\
\hline Yes & 8 & $62.5 \%$ & & \\
\hline Intraorbital extension & & & & - \\
\hline None & 139 & $78.8 \%$ & 0.1 & \\
\hline Present & 10 & $56.2 \%$ & & \\
\hline \multicolumn{5}{|l|}{ Intracranial extension } \\
\hline None & 93 & $84.4 \%$ & 0.001 & 1 \\
\hline \multirow[t]{2}{*}{ Present } & 56 & $65.3 \%$ & & $3.2(1.5-6.6)$ \\
\hline & & & & $p=0.002$ \\
\hline Kadish stage & & & & - \\
\hline Stage A/B & 33 & $96.5 \%$ & 0.03 & \\
\hline Stage C & 116 & $72.6 \%$ & & \\
\hline Previous surgical manipulation & & & & - \\
\hline No & 101 & $74.5 \%$ & 0.06 & \\
\hline Yes & 50 & $84.3 \%$ & & \\
\hline Previous radiation Therapy & & & & - \\
\hline No & 100 & $75.4 \%$ & 0.2 & \\
\hline Yes & 51 & $82.5 \%$ & & \\
\hline Previous chemotherapy & & & & - \\
\hline No & 127 & $78.8 \%$ & 0.6 & \\
\hline Yes & 23 & $73.3 \%$ & & \\
\hline \multicolumn{5}{|l|}{ Surgical margins } \\
\hline Negative & 102 & $83.7 \%$ & 0.01 & 1 \\
\hline \multirow[t]{2}{*}{ Positive (including close) } & 43 & $65.6 \%$ & & $2.2(1.1-4.7)$ \\
\hline & & & & $p=0.02$ \\
\hline
\end{tabular}

"Kadish stage and intraorbital and intracranial extension were analyzed in two mutually exclusive models.

based on local extension into the paranasal sinuses and beyond ( $\mathbf{- F i g}$. 2B-D). Early bone erosion can be difficult to appreciate on MRI scan but is readily detected on CT (-Fig. 3A, B). ENB can occasionally exhibit intratumoral calcification which is easily appreciated on CT but not on MRI (-Fig. 4). Differentiating tumor from postobstructive inflammatory changes in the paranasal sinuses may be difficult on CT, but is generally easy on MRI, particularly on the T2weighted sequence (-Figs. 3B and 5). MRI scans are also helpful in delineating intraorbital extension (-Fig. 6A, B). Subtle intracranial extension may be confirmed only at surgery, but dural enhancement (-Fig. 7) and brain edema are reliable radiological signs. The presence of cysts at the periphery of the intracranial component of tumor is an uncommon but characteristic feature of ENB (-Fig. 7).

Our analysis may have been affected by the fact that Kadish stage stratification into stage A versus B was not possible because the precise extent of anatomic involvement was not 
Table 9 Prognostic Factors for Recurrence-Free Survival

\begin{tabular}{|c|c|c|c|c|}
\hline Variable & $\begin{array}{l}\text { No. of } \\
\text { Patients }\end{array}$ & $\begin{array}{l}\text { 5-Year Recurrence- } \\
\text { Free Survival }\end{array}$ & $\begin{array}{l}\text { Univariate Analysis } \\
\text { (Log-Rank Test) }\end{array}$ & $\begin{array}{l}\text { Multivariate Analysis* } \\
\text { Relative Risk ( } 95 \% \\
\text { Confidence Intervals) }\end{array}$ \\
\hline Age & & & & - \\
\hline$<50 \mathrm{yr}$ & 77 & $62.5 \%$ & 0.7 & \\
\hline$>50 \mathrm{yr}$ & 71 & $64.9 \%$ & & \\
\hline Gender & & & & - \\
\hline Female & 58 & $67.1 \%$ & 0.7 & \\
\hline Male & 88 & $62.9 \%$ & & \\
\hline Medical problems & & & & - \\
\hline None & 142 & $63.1 \%$ & 0.3 & \\
\hline Yes & 8 & $80.0 \%$ & & \\
\hline Intraorbital Extension & & & $<0.0001$ & 1 \\
\hline None & 139 & $66.3 \%$ & & $4.2(1.6-11.5)$ \\
\hline Present & 10 & $25.9 \%$ & & $p=0.005$ \\
\hline Intracranial extension & & & 0.002 & 1 \\
\hline None & 93 & $72.5 \%$ & & $2.7(1.5-5.0)$ \\
\hline Present & 56 & $48.0 \%$ & & $p=0.002$ \\
\hline Kadish stage & & & 0.09 & - \\
\hline Stage A/B & 33 & $80.6 \%$ & & \\
\hline Stage C & 116 & $59.4 \%$ & & \\
\hline Previous surgical manipulation & & & 0.1 & - \\
\hline No & 101 & $61.6 \%$ & & \\
\hline Yes & 50 & $68.5 \%$ & & \\
\hline Previous radiation therapy & & & 0.8 & - \\
\hline No & 100 & $64.2 \%$ & & \\
\hline Yes & 51 & $64.5 \%$ & & \\
\hline Previous Chemotherapy & & & 0.6 & - \\
\hline No & 127 & $65.0 \%$ & & \\
\hline Yes & 23 & $64.4 \%$ & & \\
\hline \multicolumn{5}{|l|}{ Surgical margins } \\
\hline Negative & 102 & $71.7 \%$ & 0.01 & 1 \\
\hline \multirow[t]{2}{*}{ Positive (including close) } & 43 & $42.7 \%$ & & $2.1(1.1-4.0)$ \\
\hline & & & & $p=0.01$ \\
\hline
\end{tabular}

*Kadish stage and intraorbital and intracranial extension were analyzed in two mutually exclusive models.

available in 33 patients (22\%). Patients who are selected for CFR generally have locally advanced tumors and therefore the majority of the patients in our study were staged Kadish C. Within this group of patients, the most powerful anatomic predictor of outcome was intracranial extension. Patients who had intracranial extension of ENB were three times more likely to recur or die compared with those that did not have involvement of the dura or brain.

Intraorbital extension, on the other hand, predicted for worse RFS but was not an independent predictor of survival. This observation may be related to the possibility that variable thresholds for performing orbital exenteration may be in practice at the contributing institutions. As a general rule, orbital preservation is possible if oncologic resection with meaningful postoperative eye function is achievable in patients who have tumor involvement of bone or periosteum without gross invasion of the intraorbital contents. Preservation of the orbit in patients with skull base tumors ${ }^{24-26}$ has been a matter of some controversy, and is not without functional consequence. ${ }^{26,27}$ The rate of local recurrence in the orbit in these patients has been reported to be low, ${ }^{25,28}$ and as our analysis demonstrates, although orbital involvement was a significant predictor of recurrence, it did not significantly alter survival. While details of salvage therapy 

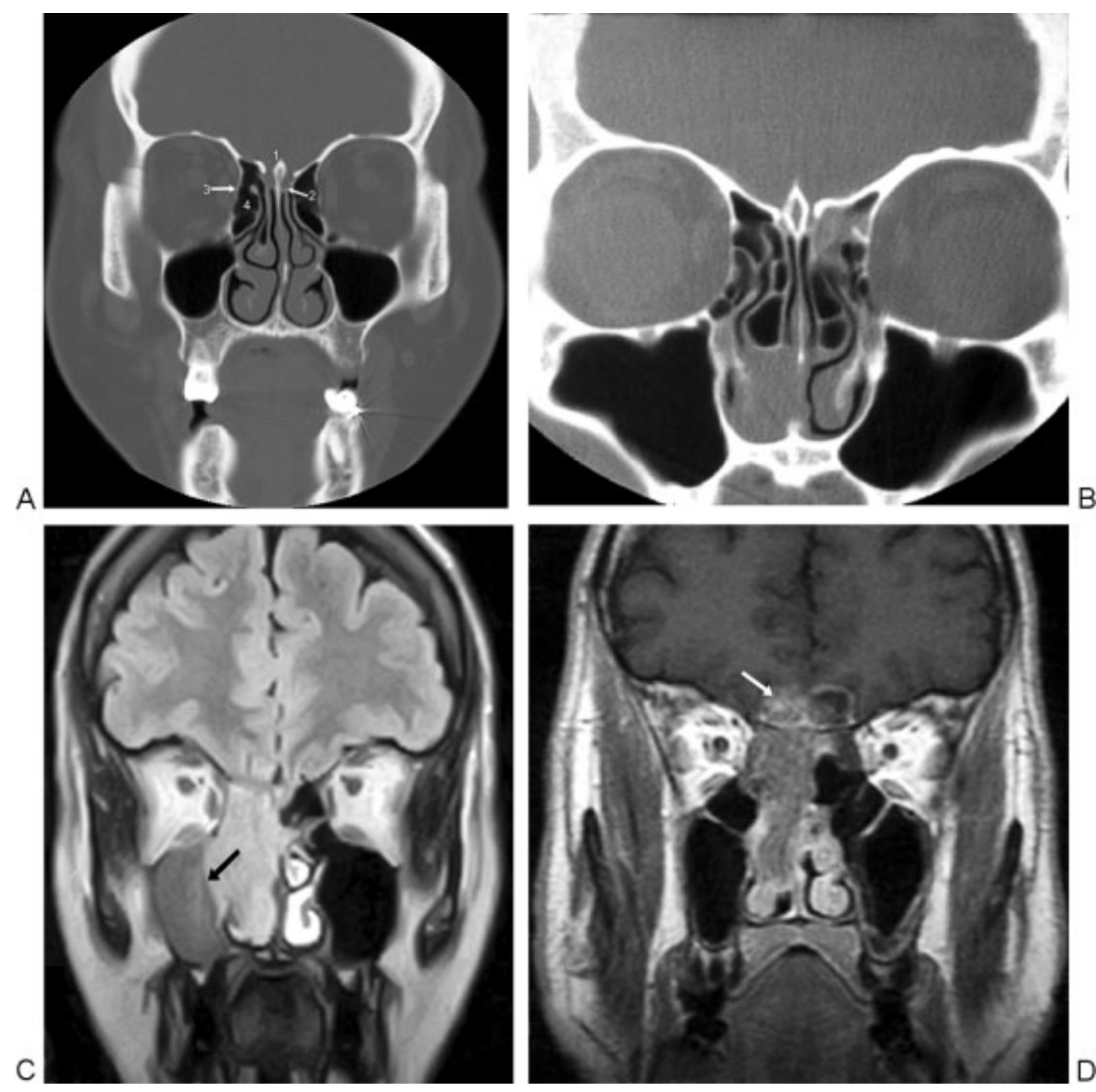

Figure 2 (A) Coronal computed tomography (CT) scan (bone window) demonstrating normal anatomy of the nasal cavity and paranasal sinuses: 1.crista galli 2.cribriform plate 3. lamina papyracea 4.ethmoid sinus. (B) A tumor that is confined to the nasal cavity is staged Kadish A. Coronal sinus CT (bone window) shows a soft tissue mass confined to the right inferior nasal cavity. (C) Involvement of the paranasal sinuses upstages the tumor to Kadish B. Coronal T2-weighted magnetic resonance imaging (MRI) scan shows tumor extension into the right medial maxillary sinus (arrow). (D) Kadish C tumors extend beyond the anatomic confines of the nasal cavity and paranasal sinuses into the orbit or cranial cavity. Coronal T1-weighted post-contrast MRI scan shows intracranial extension of tumor (arrow) with an associated peripheral cyst.
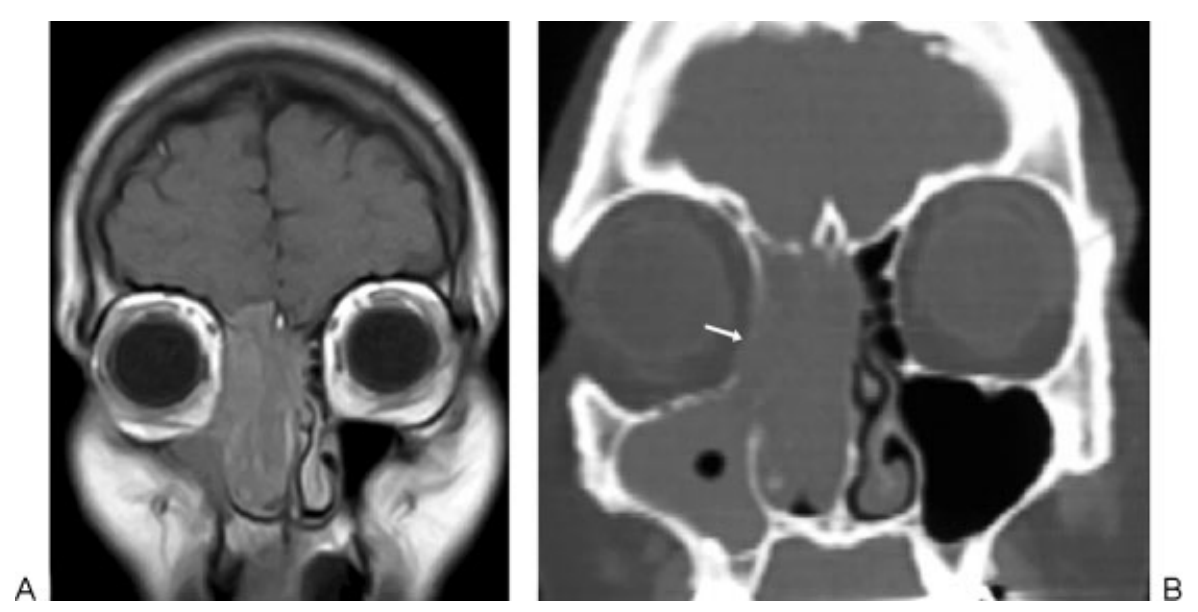

Figure 3 Subtle bone erosion that may be missed on magnetic resonance imaging (MRI) is readily detected on computed tomography (CT) scan. (A) Coronal T1-weighted postcontrast MRI scan shows soft tissue tumor in the nasal cavity and ethmoid sinus, right more than left with questionable right lamina papyracea involvement; (B) Coronal CT scan (bone window) demonstrates definite erosion of the right lamina papyracea (arrow). 


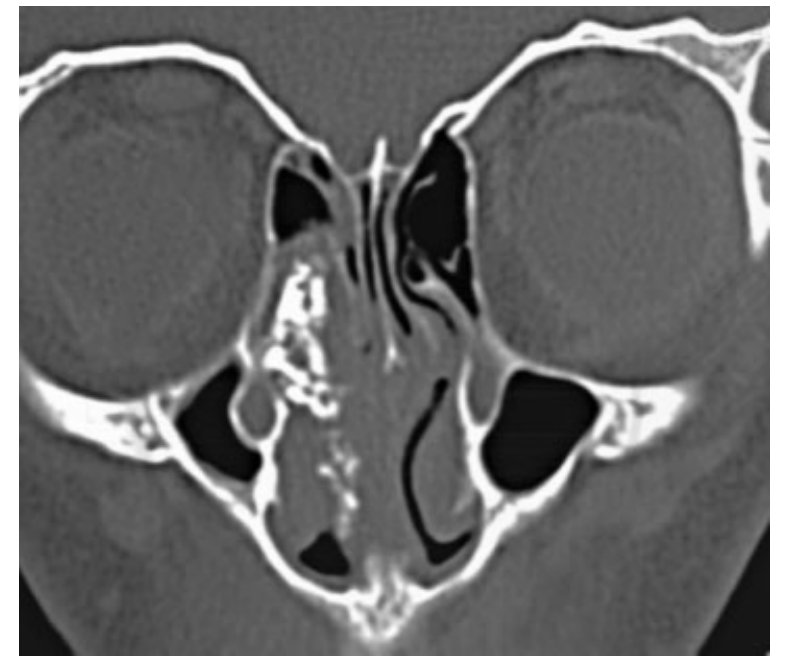

Figure 4 Coronal computed tomography scan of the sinuses (bone window) shows intratumoral calcification in an esthesioneuroblastoma of the right nasal cavity.

were not available for analysis, our observations may be explained by the possibility that local recurrence in ENB after orbital preservation may still be surgically salvageable so that eventual survival outcomes remain unaffected.

Careful patient selection is crucial in achieving satisfactory outcome after CFR. In spite of advances in preoperative assessment, intraoperative technique and postoperative care about one-third of patients develop complications, as has been reported previously. ${ }^{29-32}$ The mortality rates of the procedure are, however, low.

Various treatment combinations have been reported for treatment of ENB. On the whole, outcomes after primary nonsurgical treatment have been worse than those after CFR. ${ }^{33-35}$ Postoperative adjuvant radiation therapy (PORT) has been reported to significantly improve local control ${ }^{21}$ in retrospective comparisons. In our cohort, recurrence and survival rates in patients who received PORT were not signifi- cantly different from those that did not (5-year RFS: 64.6 vs. 64.0\%; 5-year DSS and OS: 81.1 vs. 83.9\%). These comparisons are based on retrospective data and it may be argued that patients who are selected for PORT based on a higher estimated risk of recurrence constitute a more aggressive population compared with the group that did not require PORT. In spite of this selection bias, there was only a marginal difference in outcomes in the two groups, and it is possible that PORT may have played a role in improving outcomes in the high-risk group of patients in which it was deemed necessary. The presence of close or positive surgical margins is a common indication for PORT in tumors of the head and neck. Most patients who require CFR for ENB have locally advanced tumors and although the incidence of close or positive margins in our study was $28 \%$, PORT was used in $47 \%$ of the patients. If the fact that $34 \%$ of patients had been treated with previous radiation therapy and were therefore not eligible for PORT after CFR is taken into account, it is easy to see that the decision for PORT is also influenced by factors other than the status of the surgical margins. Wide resection of these tumors in the conventional sense is generally not achievable because of constraints imposed by the anatomy of the skull base. Therefore, PORT must be considered in the management of most patients with ENB who require CFR.

Systemic chemotherapy has been recommended in the multimodality management of ENB. ${ }^{36-39}$ Neoadjuvant chemotherapy has been used at the University of Virginia for patients with Kadish $C$ tumors and an 8-year disease-free survival rate of $80.4 \%$ has been reported. ${ }^{40}$

In spite of aggressive surgical resection in the form of CFR and PORT when indicated or feasible, the 5-year recurrence rate in our patients was $36 \%$. The difficulty in ensuring recurrence-free survival is typical of ENB and is well recognized. Based on the information available in our collaborative dataset, it was not possible to analyze the patterns of recurrence. Attempts have been made to review the literature and estimate patterns of failure in ENB. ${ }^{2,41}$ An accurate estimation

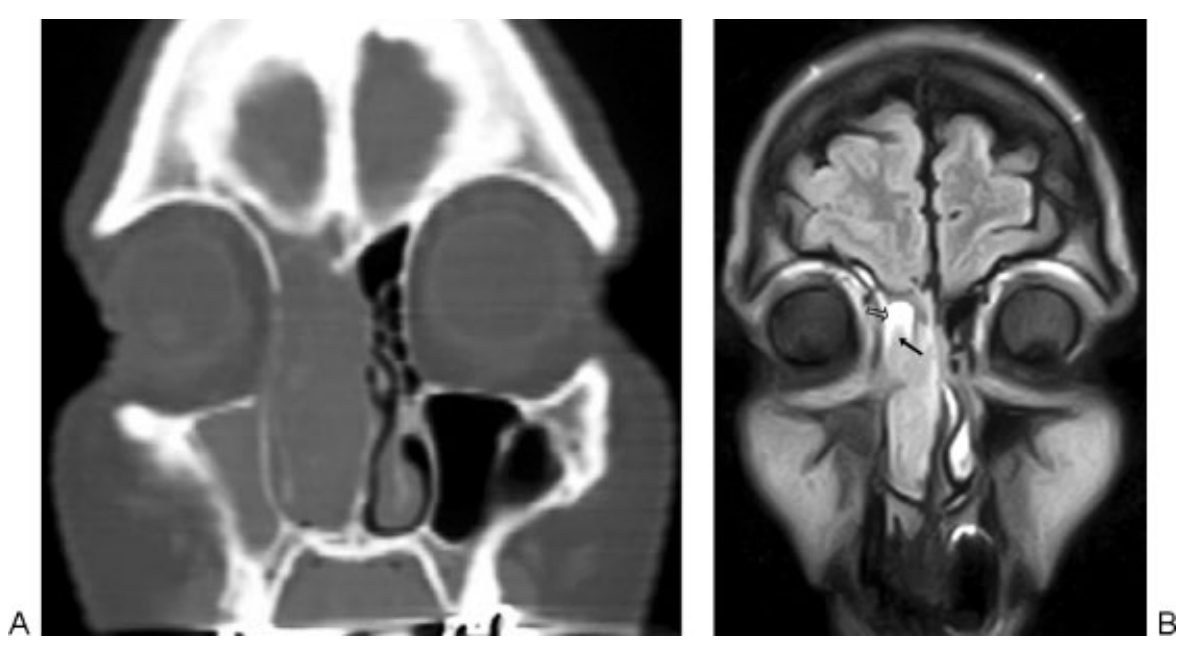

Figure 5 Differentiating tumor from postobstructive inflammatory changes in the paranasal sinuses may be difficult on computed tomography scan (A), but is generally easy on magnetic resonance imaging (MRI), particularly on the T2-weighted sequence. Coronal T2-weighted MRI scan (B) shows partial extension into the right ethmoid sinus: the tumor is grayish in appearance (closed arrow) while the postobstructive inflammatory change is bright (open arrow). 

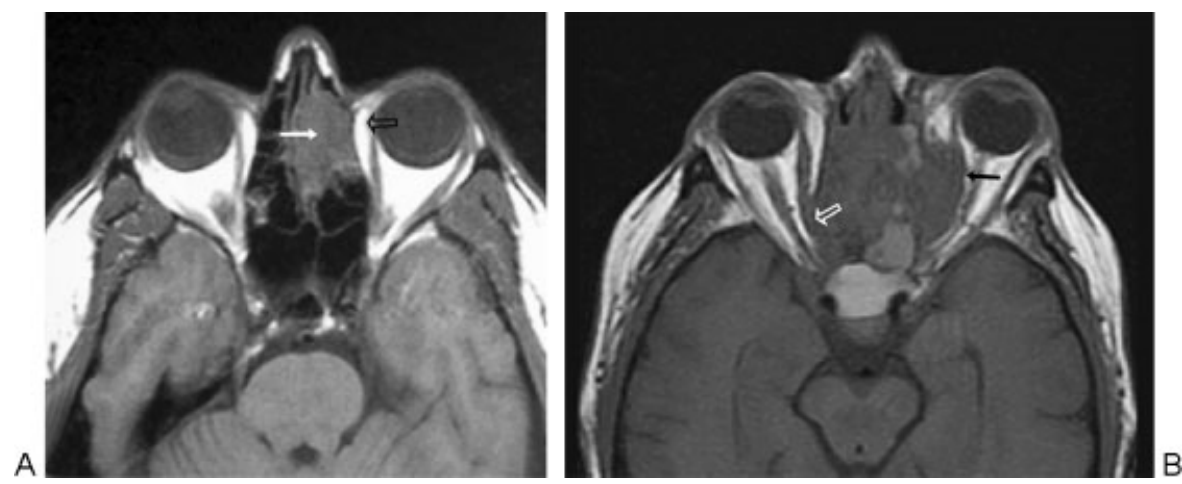

Figure 6 Magnetic resonance imaging is helpful in delineating relationship of the tumor to the contents of the orbit: (A) Axial precontrast T1-weighted image clearly shows gray tumor in the nasal cavity and ethmoid sinus (closed arrow) and normal orbital fat that appears white (open arrow) indicating no intraorbital extension of tumor. (B) Axial precontrast T1-weighted image shows bilateral orbital involvement by gray tumor. The tumor obliterates the normal fat plane medial to the medial rectus muscles indicating intraorbital extension. This finding is subtle in the right posterior orbit (open arrow) while tumor extension into the left orbit is more obvious (closed arrow).

of recurrence patterns is difficult from review of the literature because of small numbers of patients in individual reports, questionable histological diagnosis, heterogeneity in treatment, variable follow-up, and methodological differences in reporting outcomes. Local recurrence after CFR has been reported in 10 to $20 \%$ of the patients. ${ }^{21,42,43}$ The incidence of nodal metastases in ENB reported in the literature has also varied. Some authors ${ }^{13,19,44}$ cite figures less than $15 \%$ whereas others $\mathrm{s}^{6,11,40,43,45,46}$ report rates as high as $44 \%$. As might be expected, the risk for nodal metastases is higher in patients who have more advanced Kadish stage $C$ disease ${ }^{43,44}$. It has also been noted that nodal metastases tend to occur years after initial treatment and that salvage neck dissection is effective in the management of these patients. ${ }^{40,43}$ The role

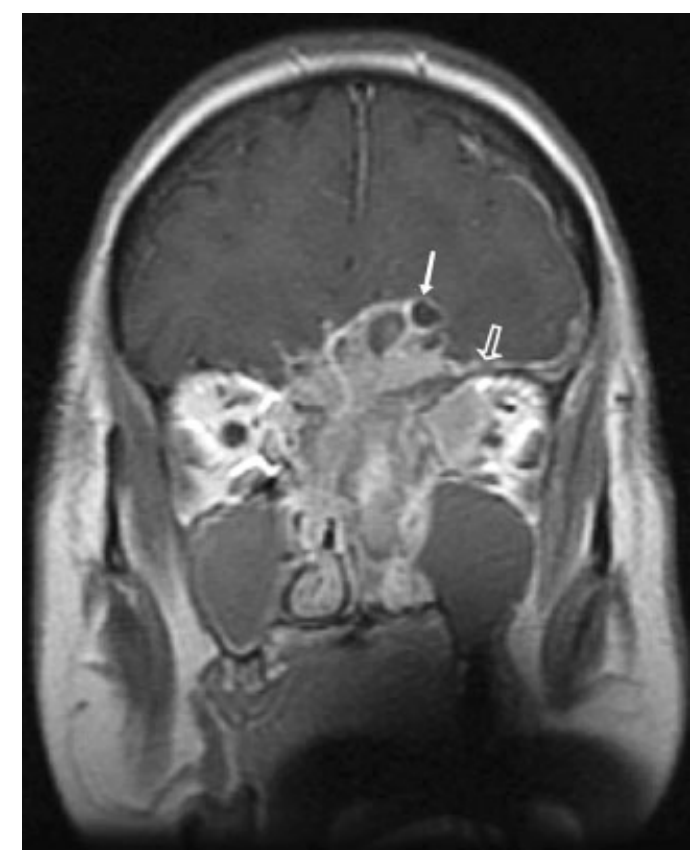

Figure 7 Coronal T1-weighted post-contrast magnetic resonance imaging scan shows obvious intracranial extension of tumor with peripheral cysts (closed arrow) as well as dural enhancement (open arrow). of elective neck treatment has been debated in the literature with proponents of elective neck irradiation ${ }^{33,45}$ citing reduced neck metastases. However, none of these reports comment on the impact of elective neck management on survival, and even institutions that have routinely used elective neck irradiation for ENB report disease-specific and overall survival rates that are lower than those reported in the current report or in other studies from authors that do not advocate routine elective neck management. ${ }^{43}$

Our study has some obvious deficits that are inherent to this approach of data collection and analysis. ${ }^{9}$ As with all other studies that include patients treated over extended time periods without review of pathology material and confirmation of reported histological diagnosis, our study is also susceptible to the possibility that patients with other histological types may have been included under the mistaken diagnosis of ENB. In addition, the duration of follow-up after initial treatment for our cohort was relatively short considering the observation that these patients remain at risk for late recurrences. Nevertheless, the larger number of patients available for analysis has allowed us to identify independent predictors of outcome based on multivariate analysis which has not been possible until now because of lack of sufficient numbers in smaller reports from individual institutions.

\section{Conclusion}

This collaborative analysis of patients treated at various institutions across the world demonstrates the efficacy of CFR in the management of ENB. Intracranial extension of disease and complete surgical excision are independent prognostic predictors of outcome.

\section{Acknowledgments}

The authors and the International Collaborative Study Group would like to acknowledge the contributions of Esther Susan N. Perez, MD, Nancy Bennett, Arlene Cooper and Bene Chan-Lin for their assistance with data entry and preparation of the manuscript. 


\section{Note}

Presented in part at the 13th Annual Meeting of the North American Skull Base Society, San Diego, February 16, 2002.

\section{References}

1 Broich G, Pagliari A, Ottaviani F. Esthesioneuroblastoma: a general review of the cases published since the discovery of the tumour in 1924. Anticancer Res 1997;17(4A):2683-2706

2 Dulguerov P, Allal AS, Calcaterra TC. Esthesioneuroblastoma: a meta-analysis and review. Lancet Oncol 2001;2(11):683-690

3 Ejaz A, Wenig BM. Sinonasal undifferentiated carcinoma: clinical and pathologic features and a discussion on classification, cellular differentiation, and differential diagnosis. Adv Anat Pathol 2005;12(3):134-143

4 Rosenthal DI, Barker JL Jr, El-Naggar AK, et al. Sinonasal malignancies with neuroendocrine differentiation: patterns of failure according to histologic phenotype. Cancer 2004;101(11):2567-2573

5 Cohen ZR, Marmor E, Fuller GN, DeMonte F. Misdiagnosis of olfactory neuroblastoma. Neurosurg Focus 2002;12(5):e3

6 Resto VA, Eisele DW, Forastiere A, Zahurak M, Lee DJ, Westra WH. Esthesioneuroblastoma: the Johns Hopkins experience. Head Neck 2000;22(6):550-558

7 Cantrell RW, Ghorayeb BY, Fitz-Hugh GS. Esthesioneuroblastoma: diagnosis and treatment. Ann Otol Rhinol Laryngol 1977;86(6 Pt 1):760-765

8 Levine PA, McLean WC, Cantrell RW. Esthesioneuroblastoma: the University of Virginia experience 1960-1985. Laryngoscope 1986;96(7):742-746

9 Patel SG, Singh B, Polluri A, et al. Craniofacial surgery for malignant skull base tumors: report of an international collaborative study. Cancer 2003;98(6):1179-1187

10 Hyams VJ. Tumors of the Upper Respiratory Tract and Ear. Washington, DC: Armed Forces Institute of Pathology; 1988

11 Morita A, Ebersold MJ, Olsen KD, Foote RL, Lewis JE, Quast LM. Esthesioneuroblastoma: prognosis and management. Neurosurgery 1993;32(5):706-714, discussion 714-715

12 Miyamoto RC, Gleich LL, Biddinger PW, Gluckman JL. Esthesioneuroblastoma and sinonasal undifferentiated carcinoma: impact of histological grading and clinical staging on survival and prognosis. Laryngoscope 2000;110(8):1262-1265

13 Dias FL, Sa GM, Lima RA, et al. Patterns of failure and outcome in esthesioneuroblastoma. Arch Otolaryngol Head Neck Surg 2003;129(11):1186-1192

14 Barnes L, Thompson LDR. Head and Neck Pathology. 69th Annual Anatomic Pathology Slide Seminar of the American Society for Clinical Pathology; New Orleans, LA2003

15 Argani P, Perez-Ordoñez B, Xiao H, Caruana SM, Huvos AG, Ladanyi M. Olfactory neuroblastoma is not related to the Ewing family of tumors: absence of EWS/FLI1 gene fusion and MIC2 expression. Am J Surg Pathol 1998;22(4):391-398

16 Carney ME, O'Reilly RC, Sholevar B, et al. Expression of the human Achaete-scute 1 gene in olfactory neuroblastoma (esthesioneuroblastoma). J Neurooncol 1995;26(1):35-43

17 Shida T, Furuya M, Nikaido T, et al. Aberrant expression of human achaete-scute homologue gene 1 in the gastrointestinal neuroendocrine carcinomas. Clin Cancer Res 2005;11(2 Pt 1):450-458

18 Mhawech P, Berczy M, Assaly M, et al. Human achaete-scute homologue (hASH1) mRNA level as a diagnostic marker to distinguish esthesioneuroblastoma from poorly differentiated tumors arising in the sinonasal tract. Am J Clin Pathol 2004;122(1): 100-105

19 Kadish S, Goodman M, Wang CC. Olfactory neuroblastoma. A clinical analysis of 17 cases. Cancer 1976;37(3):1571-1576

20 Silva EG, Butler JJ, Mackay B, Goepfert H. Neuroblastomas and neuroendocrine carcinomas of the nasal cavity: a proposed new classification. Cancer 1982;50(11):2388-2405
21 Dulguerov P, Calcaterra T. Esthesioneuroblastoma: the UCLA experience 1970-1990. Laryngoscope 1992;102(8):843-849

22 Biller HF, Lawson W, Sachdev VP, Som P. Esthesioneuroblastoma: surgical treatment without radiation. Laryngoscope 1990;100 (11):1199-1201

23 Cantù G, Solero CL, Mariani L, et al. Anterior craniofacial resection for malignant ethmoid tumors-a series of 91 patients. Head Neck 1999;21(3):185-191

24 McCary WS, Levine PA, Cantrell RW. Preservation of the eye in the treatment of sinonasal malignant neoplasms with orbital involvement. A confirmation of the original treatise. Arch Otolaryngol Head Neck Surg 1996;122(6):657-659

25 Tiwari R, van der Wal J, van der Waal I, Snow G. Studies of the anatomy and pathology of the orbit in carcinoma of the maxillary sinus and their impact on preservation of the eye in maxillectomy. Head Neck 1998;20(3):193-196

26 Imola MJ, Schramm VL Jr. Orbital preservation in surgical management of sinonasal malignancy. Laryngoscope 2002;112(8 Pt 1):1357-1365

27 Andersen PE, Kraus DH, Arbit E, Shah JP. Management of the orbit during anterior fossa craniofacial resection. Arch Otolaryngol Head Neck Surg 1996;122(12):1305-1307

28 Iannetti G, Valentini V, Rinna C, Ventucci E, Marianetti TM. Ethmoido-orbital tumors: our experience. J Craniofac Surg 2005;16(6):1085-1091

29 Ganly I, Patel SG, Singh B, et al. Complications of craniofacial resection for malignant tumors of the skull base: report of an International Collaborative Study. Head Neck 2005;27(6):445-451

30 Irish J, Dasgupta R, Freeman J, et al. Outcome and analysis of the surgical management of esthesioneuroblastoma. J Otolaryngol 1997;26(1):1-7

31 Solero CL, DiMeco F, Sampath P, et al. Combined anterior craniofacial resection for tumors involving the cribriform plate: early postoperative complications and technical considerations. Neurosurgery 2000;47(6):1296-1304, discussion 1304-1305

32 Levine PA, Gallagher R, Cantrell RW. Esthesioneuroblastoma: reflections of a 21-year experience. Laryngoscope 1999;109 (10):1539-1543

33 Monroe AT, Hinerman RW, Amdur RJ, Morris CG, Mendenhall WM. Radiation therapy for esthesioneuroblastoma: rationale for elective neck irradiation. Head Neck 2003;25(7):529-534

34 Eich HT, Staar S, Micke O, Eich PD, Stützer H, Müller R. Radiotherapy of esthesioneuroblastoma. Int J Radiat Oncol Biol Phys 2001;49 (1):155-160

35 Gruber G, Laedrach K, Baumert B, Caversaccio M, Raveh J, Greiner R. Esthesioneuroblastoma: irradiation alone and surgery alone are not enough. Int J Radiat Oncol Biol Phys 2002;54(2):486-491

36 Polonowski JM, Brasnu D, Roux FX, Bassot V. Esthesioneuroblastoma. Complete tumor response after induction chemotherapy. Ear Nose Throat J 1990;69(11):743-746

37 McElroy EA Jr, Buckner JC, Lewis JE. Chemotherapy for advanced esthesioneuroblastoma: the Mayo Clinic experience. Neurosurgery 1998;42(5):1023-1027, discussion 1027-1028

38 Polin RS, Sheehan JP, Chenelle AG, et al. The role of preoperative adjuvant treatment in the management of esthesioneuroblastoma: the University of Virginia experience. Neurosurgery 1998;42(5):1029-1037

39 Sheehan JM, Sheehan JP, Jane JA Sr, Polin RS. Chemotherapy for esthesioneuroblastomas. Neurosurg Clin N Am 2000;11 (4):693-701

40 Oskouian RJ Jr, Jane JA Sr, Dumont AS, Sheehan JM, Laurent JJ, Levine PA. Esthesioneuroblastoma: clinical presentation, radiological, and pathological features, treatment, review of the literature, and the University of Virginia experience. Neurosurg Focus 2002;12(5):e4

41 Rinaldo A, Ferlito A, Shaha AR, Wei WI, Lund VJ. Esthesioneuroblastoma and cervical lymph node metastases: clinical and therapeutic implications. Acta Otolaryngol 2002;122(2):215-221 
42 Foote RL, Morita A, Ebersold MJ, et al. Esthesioneuroblastoma: the role of adjuvant radiation therapy. Int J Radiat Oncol Biol Phys 1993;27(4):835-842

43 Diaz EM Jr, Johnigan RH III, Pero C, et al. Olfactory neuroblastoma: the 22-year experience at one comprehensive cancer center. Head Neck 2005;27(2):138-149
44 Elkon D, Hightower SI, Lim ML, Cantrell RW, Constable WC. Esthesioneuroblastoma. Cancer 1979;44(3):1087-1094

45 Beitler JJ, Fass DE, Brenner HA, et al. Esthesioneuroblastoma: is there a role for elective neck treatment? Head Neck 1991;13(4):321-326

46 Davis RE, Weissler MC. Esthesioneuroblastoma and neck metastasis. Head Neck 1992;14(6):477-482 